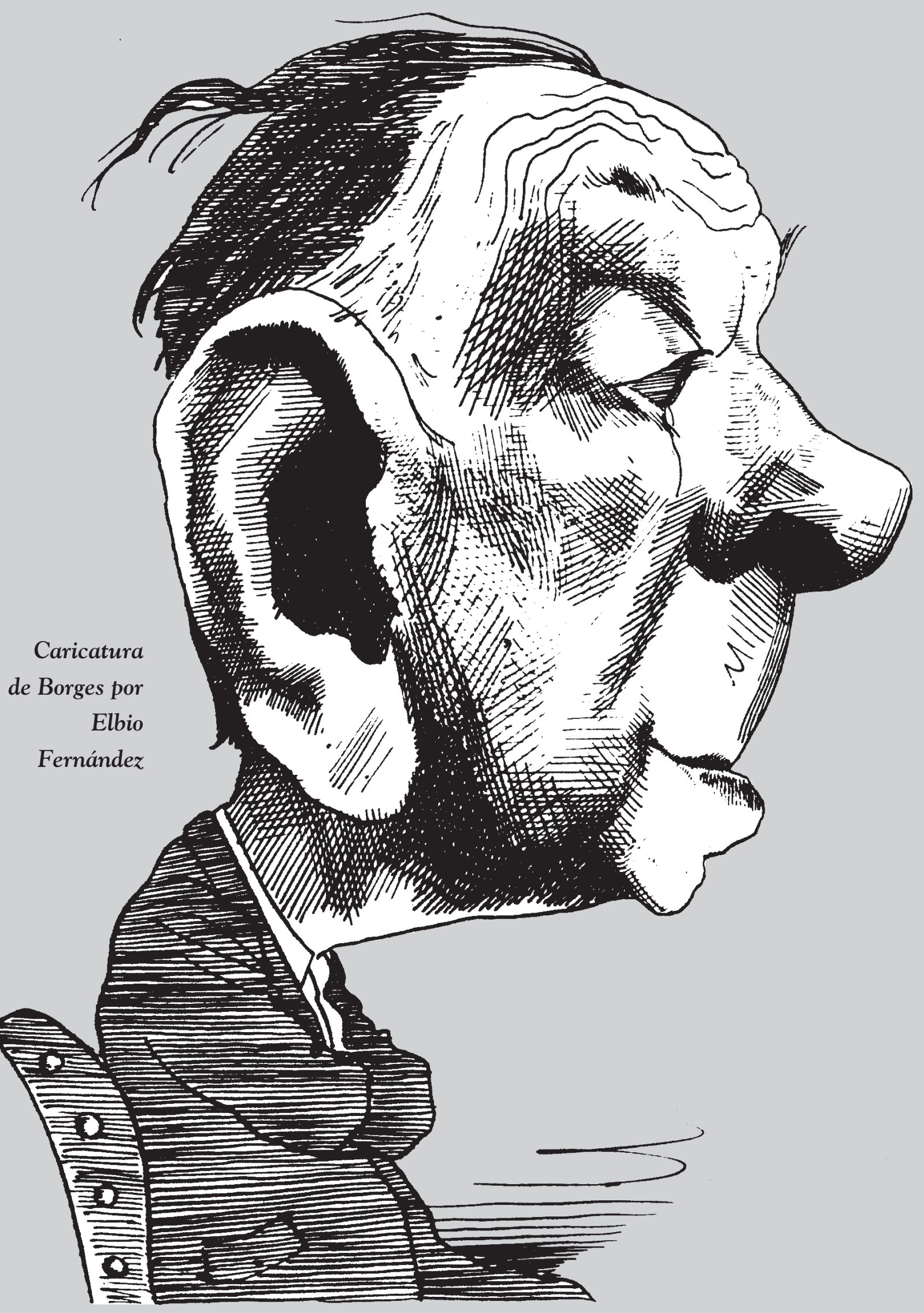




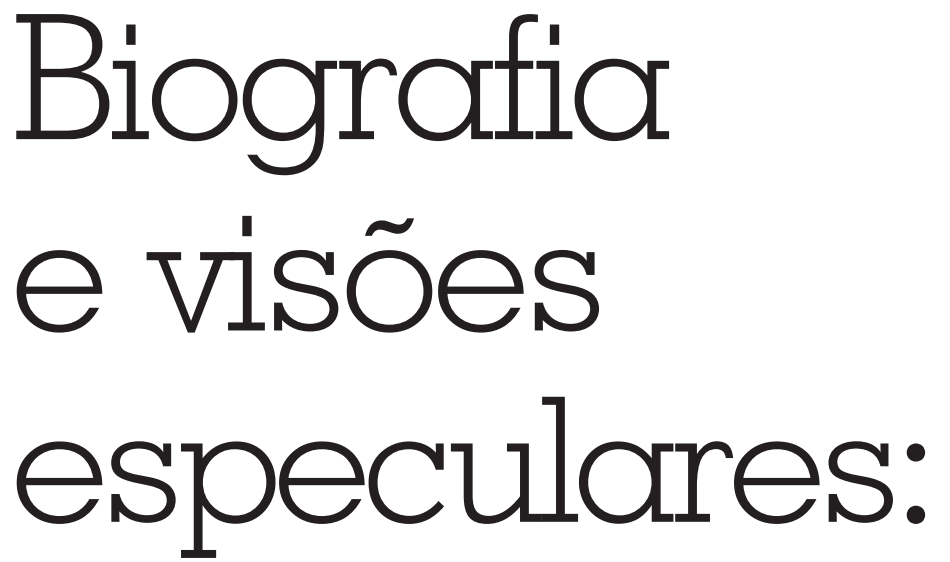

LEOPOLDO $M$.

BERNUCCI é professor

da University of Colorado

at Boulder (EUA).

\section{LEOPOLDOM. BERNUCCI}

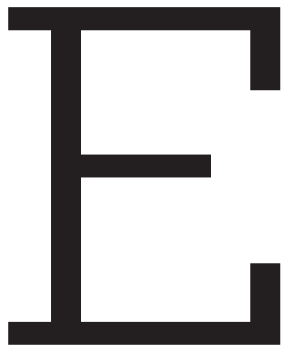

m seu reduzido e único texto

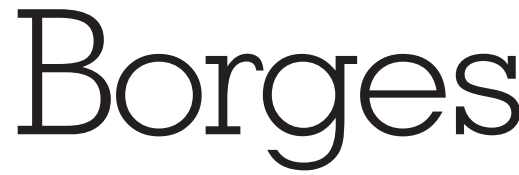

claramente autobiográfico,

de 1970 , contendo umas par-

cas notas memorialísticas nas páginas de The New Yorker, Borges nunca chegou a penetrar profundamente em sua vida pessoal e muito menos em seus assuntos amorosos (1). Compreendese talvez o porquê dessa atitude: como certa vez disse o próprio Borges, para se conhecer a vida de alguém nãoé preciso que ela seja narrada. O que, então, o levou a esboçar alguns traços de sua própria autobiografia do ponto de vista estritamente histórico? Uma possível resposta a esta pergunta poderia estar nas páginas de uma resenha, escrita por ele em 1937, sobre o inconcluso livro autobiográfico Something of Myself, de Rudyard Kipling:

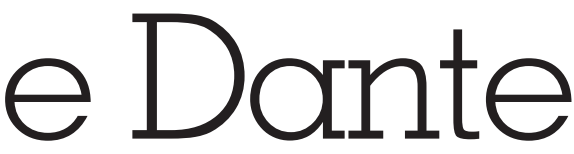


"Entiendo que el interés de cualquier autobiografía es de orden psicológico, yque el hecho de omitir ciertos rasgos no es menos teipico de un hombre que el de abundar en ellos. Entiendo que los hechos valen como ilustración del carácter y que el narrador puede silenciar los que quiere. Regreso, siempre, a la conclusión de Mark Twain, que tanta noches dedicó a este problema de la autobiografía. 'No es posible que un hombre cuente la verdad sobre él mismo,o deje de comunicar al lector la verdad sobre él mismo"" (Textos Cautivos, p. 108).

A noção que aqui oferece Twain da autobiografia nos obriga a perguntar por que e como Borges concebe a sua própria auto-representação de modo oblíquo e dissimulado. Contraditoriamente, por um lado, ele reluta em se expor, e, por outro, deseja revelar-se, sendo que a contradição nesse particular responde a um processo paradoxal de psicanálise. Tanto a autocensura quanto o ocultamento terminam, no seu caso, por durar pouco, como também costuma acontecer no caso do paciente que "utiliza as mesmas técnicas [discursivas] de condensação, deslocamento, codificação e distorção, identificadas por Freud, como estratégias psicológicas usadas nas sessões de interpretação de sonhos, para mascarar o latente (e real) significado de um sonho que estaria por trás do nível literal ou manifesto da narrativa onírica" (2). Acrescese a esta situação ambígua o desprezo de Borges pelas teorias freudianas; rejeição, aliás, bem documentada na sua biografia e que mereceria maior atenção por parte da crítica literária.

Comparativamente, a predileção do escritor argentino por Jung não parece ser uma tática bem ensaiada de scholar querendo suplantar Freud e garantindo para si próprio, nesse processo seletivo, ao menos uma grande autoridade, ainda que única, do mundo da psicanálise. Considerando a enorme erudição de Borges, suas leituras diversas e seus interesses interdisciplinares, percebe-se que a falta de um expert da psicanálise, na galeria dos grandes nomes admirados pelo nosso autor, era-lhe intole- rável. Ainda mais ele, que no campo do saber era eclético, curioso e ousado. E assim sendo, Borges encontra em Jung uma autoridade de peso que estivesse à altura daquele problemático doutor Freud, cujas teorias, certamente, incomodaram o escritor com revelações perturbadoras sobre o seu próprio eu e que estariam relacionadas ao trauma de Borges, depois da morte do pai, à sua sexualidade e fobia de aparecer em público e, ironicamente, ao seu medo de máscaras:

"Burgin: Eu entendo que o senhor não gosta também muito de Freud.

Borges: Não, eu sempre o detestei. Mas eu sempre fui um ávido leitor de Jung. Li Jung da mesma maneira, digamos, como teria lido The Golden Bough de [James] Frazer; eu o lia como um tipo de mitologia; ou como um tipo de museu ou enciclopédia de pensamentos curiosos.

Burgin: Quando o senhor diz que detesta Freud, o que realmente quer dizer?

Borges: Eu o considero uma espécie de louco, não é mesmo? Um homem lutando para resolver uma obsessão sexual. Bem, talvez ele não estivesse levando isso a sério. Talvez este estivesse fazendo-o como uma espécie de jogo. Eu tentei lê-lo e, até certo ponto, não pude deixar de pensar nele como se ele fosse um charlatão ou um louco. Afinal, o mundo é por demais complexo para ser reduzido a um mero esquema genérico. Porém, em Jung, é claro, Jung eu li muito mais obras dele que de Freud, e em Jung você sente um espírito muito mais largo e acolhedor. No caso de Freud, tudo se resume a uns poucos fatos francamente desagradáveis. Mas, claro, pode ser minha mera ignorância ou meu preconceito" (Rodríguez Monegal, Jorge Luis Borges, p. 22) (3).

Na obra de Borges, a noção de autobiografia está ligada à busca do autoconhecimento. Mas tal busca é interminável e vai além das fronteiras da escritura autobiográfica, assimilando vidas de outros escritores. Borges, que agora se aventura em terreno alheio, não pode evitar que sua face 
se veja refletida na dos outros. Tal é o grau de complexidade da escritura autobiográfica borgiana, que se torna necessário explorar aspectos de sua vida em obras de Borges consideradas menos autobiográficas aparentemente (4).

No corpo deste ensaio, trataremos das figurações do eu nos textos de Borges segundo a visão originalíssima que o escritor tem da autobiografia, informada pelas estratégias de ocultamento e revelação. Se em princípio ele rejeitava uma teoria redutiva, nos moldes do século XIX, como a da equivalência entre vida e obra do autor, não obstante Borges nunca se furtou a rever essa equivalência; e assim, o ímpeto de revisitar tantas vezes essa equação pode ser interpretado como uma busca de autoconhecimento.

Mesmo tendo mencionado Freud aqui, não queremos com isso dar a impressão de estar sugerindo mais uma teoria psicanalítica para interpretar as peculiaridades do escritor argentino. $\mathrm{O}$ que realmente nos interessa é ver até que ponto o autoconhecimento borgiano se manifesta não só através da consciência clara do seu ser, mas também através da urgência de comunicar fragmentos do seu eu, sempre de modo astuto e a qualquer custo na sua escritura. Aparentemente, Borges como poeta e crítico exerce duas atividades, ao escrever sobre si mesmo e sobre a vida e a obra de outros escritores. Mas é só na aparência, porque na verdade elas são insuperavelmente uma só. Dessa maneira, através da vida e da literatura dos outros, ele também escreve sobre a sua pessoa; sendo que a chave para desvendar esse paradoxo estaria na profunda compreensão que Borges possui da tradição literária e do papel que a sua própria literatura desempenha num contexto mais global. Na comunhão geral, em que através dos tempos todos os livros se tornam uma só obra universal, compartilhada por gerações de inúmeros escritores, e onde vamos encontrar aquele espírito de desprendimento ou abnegação e de autoconhecimento que tanto o caracterizou. Borges se reconhece em Emerson, Whitman, Stevenson, Kafka, e em outros escritores, mas sobretudo em Dante, principalmente através de um de seus contos mais famosos, "El Aleph" (1945) e os Nueve Ensayos Dantescos (1982) (5).

Borges sempre apostou alto na sua presença autoral e, nos vários poemas, contos e, é claro, nos seus instigantes ensaios, ele muitas vezes gostou de jogos autobiográficos arriscados e perigosos. Além do mais como o seu bem conhecido experimentalismo literário parece demonstrar, é precisamente no centro dessa atividade lúdica que deveríamos situar a literatura borgiana. Ora especulando sobre uma nova teoria do tempo, ora discorrendo sobre uma noção não tão inusitada da influência literária ou sobre uma idéia original acerca do status ficcional do leitor, Borges sempre foi um jogador audaz. Acreditamos que a ameaça iminente e a instabilidade sob as quais eram colocadas suas hipóteses filosóficas e literárias faziam parte da sua principal motivação para escrever. Subterfúgios, máscaras, pseudônimos, imagens especulares, distorções, falsas alusões, embustes, nomes duplos, tudo contribuiu para criar simulacros e levar a sua representação artística até as últimas consequiências. Provavelmente, este foi o único modo peloqual Borges pôde conceber o seu universo literário, impregnando-o de uma visão critica e irônica que lhe permitiu avaliar os pontos fortes e fracos de sua criação. Somos tentados a concluir, portanto, que o evanescente eu em Borges deriva da noção de que a escritura (auto)biográfica também faz parte do jogo literário do nosso autor. Neste jogo, cujos parceiros são os leitores, os jogadores não têm nada a perder. Infelizmente, a sorte de Borges é outra.

Uma vez que o nosso autor percebeu que seria inútil extirpar a presença do eu autobiográfico da sua ficção e poesia, ele teve que resolver uma questão embaraçosa: como evitar se expor de forma aberta ao leitor? Para alguém que preservava a sua mais íntima privacidade, a estratégia literária adotada por ele era sem dúvida arriscada. Porém, a idéia de ser "caçado"-como um aventureiro que tenta escapar da autorevelação e ao mesmo tempo se delicia com
4 Um rápido exame do desenvolvimento da poesia de Borges seria suficiente para de monstrar como durante vários anos a sua poesia se tornou cada vez mais autobiogrática. Se considerarmos a possibilidade de que na sua poesia a voz do eu lírico coincide com a do autor, estaremos principalmente ressaltando as reteências históricas da vida de Borges (e.g., o passado heró co de seus avós, lugares visitados e livros lidos por ele, cida des onde moroul.

5 Para as obras ainda não traduzidas em português, a tradução que aparece no presente trabalho será sempre nossa. Os Nueve Ensaios Dantescos se encontram nas Obras Completas $(O C$, II) de Borges. Em vários lugares, Borges su gere um modo de identifica cão entre sua obra e a de Emerson "uma atividade da mente"), de Whitman (regionaismo vs, universalismol, de Stevenson /que será - a a partir de Fervor de Buenos Aires um dos seus grandes precursores) e de Kafka (que influenciou a literatura fantástica do escritor argentinol. 
6 Sob seis pseudônimos, Borge escreveu vários ensaios para Revista Multicolor de los Sábados. Consultar Borges en 'Re vista Multicolor'. Para complcar ainda mais as coisas, al guns textos não escritos por Borges e publicados no número de El Hogarde 27/1/1939 - revista na qual Borges colaborou de 1936 a 1939 - fo ram incorretamente atribuídos a ele. Ver Textos Cautivos, p. 24

7 Obviamente, aqui esta noção (ricorso) vem da Scienza Nuova de Vico. Em "El Evangelio según Marcos" (1970), apagando as linhas entre ficção e realidade histórica ou personagem ficcional e leitor, Borges apresenta e testa de modo magistral a sua teoria sobre o cance lamento das fronteiras discursivas. Ele assim o faz, através de um conto, o que quer dizer, de um texto ficcional mas, ironicamente, através de uma ficcõo extraordinariamente realista. Nesse conto, em parficular, o protagonista, Baltasar Espinosa, leitor da Bíblia, torna-se personagem de sua pró pria leitura. Ao ler para sua audiência uma passagem qugural de São Marcos sobre a agonia e morte de Cristo Baltasar "entra" na história, contada duas vezes, para inescapavelmente ser identificado pelos seu ouvintes com Cris to e ver-se "preso", "ficcionalizado" na narrativa bíblica. A questão mais espinhosa para o leitor, porém, não é se a leitura da Bíblia deveria ser conside rada ficção ou história, mas quanto Borges quer nos fazer acreditar na sua ficcionalidade /ou historicidade.

8 Ver Out of Context, p. 2

9 As observações de Borges IOC, II, p. 15) se referem ao poema de Whitman, "When Heard at the Close of the Day", citado no ensaio de D. Balderston (p. 34). O escritor argentino também expressou uma idéia semelhante em "Emma Zunz" (El Aleph): "La historia era increíble, en efecto, pero se impuso a todos, por que sustancialmente era cierta. Verdadero era el tono de Emm Zunz, verdadero el pudor, verdadero el odio" IOC, I, p. 568).

10 Já perto de concluir o presente ensaio, demos com um artigo de Santiago Rojas, publicado em 1995, que desenvolve um modelo semelhante ao nosso especialmente naquilo que se retere aos dois modos de autofiguração em Borges. Acreditamos, contudo, que o tercei- a atenção prestada a suas aventuras - deve tê-lo agradado imensamente. Ademais, ele se imiscui na sua escritura não só com o propósito de uma auto-revelação lúdica, mas - o que é mais importante - com o peculiar objetivo de realizar uma confissão dissimulada. Nesse movimento estranho e ambivalente, uma vez que ele decide revelar-se ao leitor, ele também tem que, necessariamente, esconder-se. Não deveria surpreender-nos, assim, que quanto mais Borges se oculta de nós leitores, mais ele se torna aparente.

Essa estratégia de ocultamento e revelação se aplica a sua produção lírica, ficcional e ensaística (6). Vale a pena notar que as três áreas da escritura borgiana, geralmente melhor delineadas em outros escritores que nele, formam um só canal através do qual flui a energia de uma única matriz literária no que diz respeito às linguagens empregadas. Daí a dificuldade de dissociar uma área da outra, isto é, de ler seus contos sem considerar a sua poesia e seus ensaios; ou lidar com sua poesia sem ao menos considerar seus contos. Eliminando fronteiras genéricas, há na literatura de Borges fluxos recorrentes - mas nunca iguais - e temas, marcas estilísticas e modos de dicção (7).

"Não há dúvida que, hoje em dia, é possível reconsiderar a questão da relação da ficção borgiana com as realidades além do texto", como propõe Daniel Balderstol (8). Sob o signo da irrealidade e do nada, fica aquela impressão de que, no passado, alguns dos críticos de Borges trataram sua literatura mais como uma espécie de "ficção científica" do que uma coletânea de textos, na qual a realidade, inclusive a realidade da vida do autor, estaria sujeita de modo caprichoso à ficção, somente para ser reescrita e manipulada.

Seria absurdo negar o papel que o imaginário desempenha num universo literário tão rico quanto o de Borges. Embora se reconheça nele uma mente literariamente lúcida, sempre voltada para resolução de "problemas" e que procura controlar a sua expressividade, embora seja essa mesma mente a que também cria universos fantás- ticos ou objetos não-existentes, competindo com realidades históricas, estamos no entanto convencidos de que algumas zonas obscuras, silenciosas e auto-referenciais de sua biografia podem lançar luz sobre muitos aspectos literários de sua obra. Se houver, em “El Aleph”, por exemplo, e acreditamos que haja, boas razões para depreciar a idéia da existência histórica da mulher que aparece como Beatriz Viterbo - conforme sugere Harold Bloom ao analisar a Beatrice de Dante - haverá também razões de sobra para aceitar que a imagem de Beatriz Viterbo corresponde à representação verossímil de Estela Canto, o grande amor do escritor na década de 40. Todavia, seria preferível conceber o modo de representação artística, em geral, como Borges o conceituou para o caso da poesia, isto é, assumindo que "o poema ganha em estatura se descobrirmos que é a expressão de um desejo, e não a história de um acontecimento" (9).

"Escrevemos" - recorda Octavio Paz "para sermos o que somos e o que não somos. Em qualquer um dos casos, procuramos a nós mesmos" (p. 143). Em Borges, não pode existir autoconhecimento sem auto-revelação, e na medida em que ele se conhece através de outros - como já vimos - o escritor sorrateiramente nos permite penetrar pouco a pouco na sua vida privada. Discretamente, Borges se apresenta ao seu leitor debaixo de quatro máscaras ou personae (10). Primeiro, em alguns de seus poemas e contos, o seu nome, Borges, estaria presente mas de forma reservada. Com certeza, não há nenhuma timidez neste gesto, embora a participação ficcional de Borges como personagem seja limitada, e aliás passiva, em contos como "Hombre de la Esquina Rosada”, "La Forma de la Espada”, “E1 Zahir", “E1 Indigno”, “Juan Muraña” e "El Sueño de Pedro Henríquez Ureña". Nem poderíamos encontrar dados biográficos muito óbvios, associados com a sua persona poética ou ficcional, já que esses não indicam informações do tipo familiar ou privado. O seu nome, indiscutivelmente, é Borges, mas apesar dessa constatação ele não é o mesmo Borges que re- 
conhecemos dentro e fora de sua literatura

Em acentuado contraste com essa parcial e mínima projeção autoral, encontrase o segundo modo de auto-inclusão, no qual Borges ocupa um lugar central como protagonista ou objeto de representação de sua poesia. A timidez do primeiro modo é substituída, conseqüentemente, por uma persona poética mais ativa ou participante na sua prosa ("El Aleph", "Borges y Yo") ou em seus poemas ("El Otro", "Veinticinco de Agosto, 1983").

Numa terceira forma ainda de disfarce, ele se faz presente ao apagar seu nome somente para logo impor os aspectos de sua biografia facilmente reconhecíveis por nós (“El Sur”). Que Borges possa deslizar-se com uma certa desenvoltura frente aos nossos olhos e finja ser anônimo, quando na verdade ele é o Borges enciclopédico que todos nós reconhecemos em "Tlön, Uqbar, Orbis Tertius", é algo que tampouco

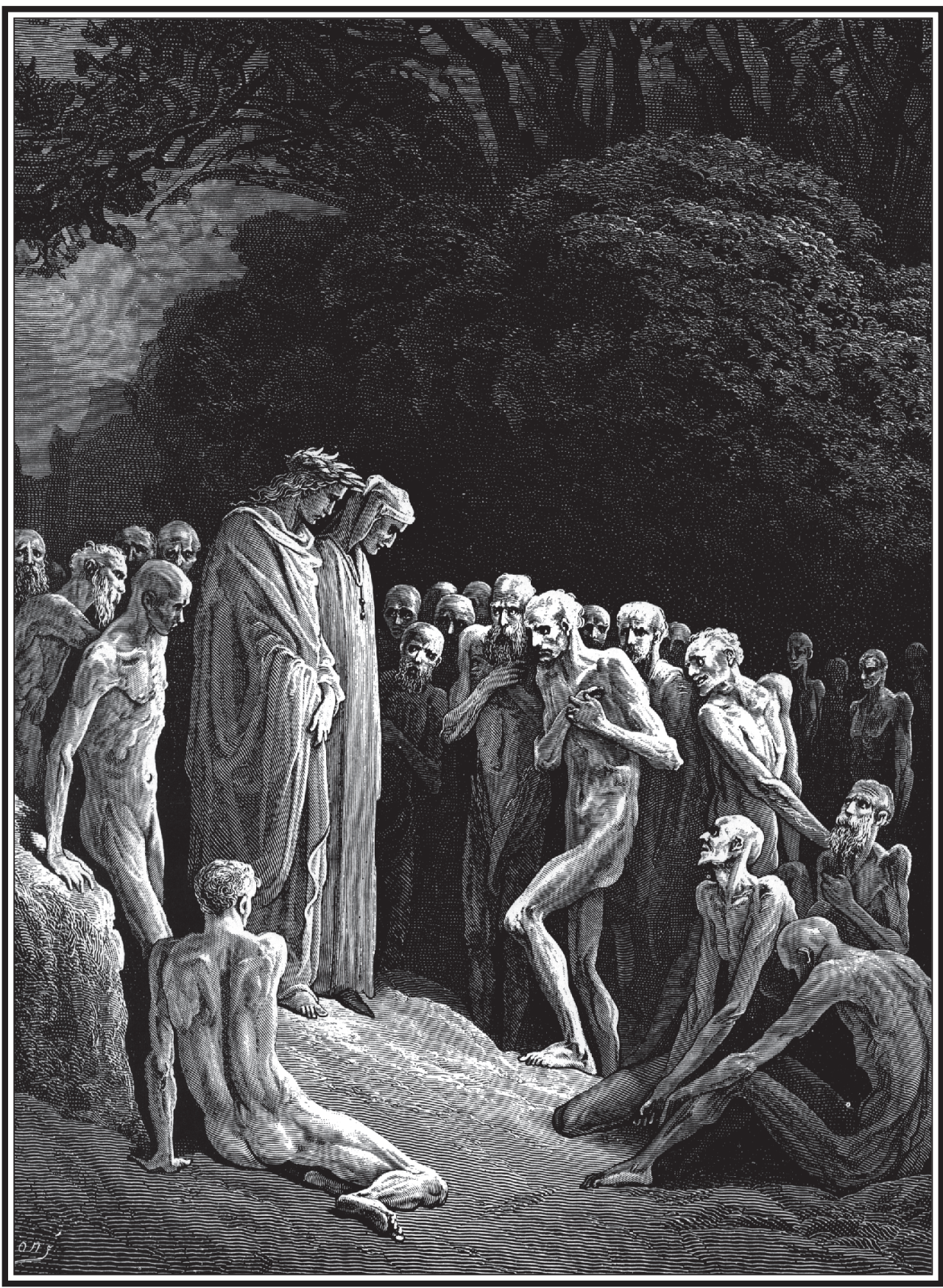

\section{Ilustração da}

Divina

Comédia por

Paul Gustave

Dore ro modo de Rojas constitui um mero desvio do segundo construído por ele. Ver "El Desdoblamiento Creador Personaje en Borges: Usos y Efectos de Creación", in Confluencia, 11, 1, 1995, po. 75-88. Consultar também ensaio de Rodríguez Monega "La Escritura como Máscara", em Borges por Él Mismo, pp. 17-32. 
11 Ver Signs of Borges, p. 33

12 Qualquer que seja o modo de interpretar a sua teoria, para Borges a palavra "leitor" deve ser também entendida como "autor", ou vice-versa. O pró prio Borges nos deu suficientes provas dessa verdade em ao menos quatro textos famosos l"Hombre de la Esquina Rosada". "Historia de Rosendo Juárez", "El Evangelio según Marcos" e "Borges y Yo"l. Em uma entrevista (1968) a Rito Guibert, Borges declarou: " cuando Walter Whitman escribió Leaves of Gras escribió una especie de epopeya cuyo protagonista era Walt Whitman, pero no e Whitman que escribía, sino hombre que el autor hubiero querido ser. Eso no lo digo desde luego en contra de Wa Whitman, pero pienso que habría que leer su obra, no como la confesión de un hombre del siglo XIX, sino como la epopeya de un personaje imaginario, un personaje utó pico, que es hasta cierto punto una magnificación y proyección del autor como la del lector". Ver Alazraki, pp. 336-57, citado a partir de Bloom. The Western Canon, p. 477

130 deslocamento textual aqui é na verdade, muito mais complexo do que a nossa discussão poderia abarcar. "Exame de la Obra de Herbert Quain realiza empréstimos textuais da resenha, escrita por Borges, do livro Excellent Intentions de Richard Hull e publicada por $E$ Hogar (Buenos Aires) em 15 4/1938. Ver Textos Cautivos, pp. $227-8$ e 283-4.

14 Balderston, "The 'Fecal Dialectic $^{\prime \prime \prime}$, p. 35.

15 Para enfatizar a auto referencialidade de Borges em "El Aleph", citamo-lo numa entrevista com Antonio Carrizo: "El Aleph' creo que es un lindo cuento. 'El Aleph' es el de un punto en espacio, en el cuo está contenido todo el espacio. Y eso está tomado de la ideo de la eternidad, que es un instante en el cual esta contenido todo el tiempo. Yo apliqué al espacio lo que los teólogos han aplicado al tiempo. Viene a ser como una eternidad de espacio. Yluego entreveré otras cosas: había estado muy eno morado de Beatriz Viterbo; ello había muerto... En fin, puse ele mentos autobiográficos en ese cuento. Como hay que poner siempre, para que suenen convincentes las cosas" (elipse no original, p. 237)

Mais significativa é a definição que Borges dá a um de seus pode ser negado. Neste caso, o papel textual do narrador coincide com o papel social do autor (isto é, Borges como escritor e amigo íntimo de Adolfo Bioy Casares). De novo, o nome Borges não aparece, embora uma parte de sua autobiografia, mesmo fragmentada, seja facilmente reconhecida. Sylvia Molloy escreve que "todos os personagens borgianos, depois de Pierre Menard, são construções verbais evidentes" (11). Se tomadas fora do contexto, o qual não nos interessa no momento, suas palavras definem precisamente os personagens de Borges em geral, e também a si mesmo como tal, na medida em que as palavras da estudiosa reiteram a conhecida frase do escritor: "se os personagens de um conto podem ser leitores ou espectadores, então nós, seus leitores ou espectadores, podemos ser fictícios" (12).

Finalmente, pela transformação de sua voz crítica em voz ficcional, a presença incisiva do discurso ensaístico de Borges na sua ficção ("Examen de la Obra de Herbert Quain”) comprova a marca essencialmente autobiográfica deixada nos seus contos. Sem maiores esforços, Borges transita entre a crítica e a ficção.

Como poderíamos julgar esse movimento? Se quiséssemos acreditar que o seu discurso ensaístico se ficcionaliza, o que de fato às vezes ocorre, deveríamos também aceitar a sua visão paródica do discurso crítico literário, já que “Examen. ...” pertence a Ficciones (1944) e não a um de seus livros de ensaios críticos, tais como Discusion (1932) ou Otras Inquisiciones (1952) (13). Mas poderíamos também ler "Examen..." como uma espécie de arte poética de Borges, ou considerar ainda que sua prática literária cancela as demarcações genéricas entre ensaio e ficção, como em "Pierre Menard, Autor del Quijote".

Uma coisa é historiar a visão que tem Borges de uma "fácil distinção entre vida e obra [supondo] que não poderia haver um trânsito imaginativo entre uma e outra" (14); outra coisa seria interpretar a mesma visão no contexto mais amplo de toda sua obra. Comentando o fracasso dos biógrafos de Walt Whitman que não puderam chegar a uma compreensão cabal sobre as minúcias implícitas na noção de correspondência entre voz autoral e voz narratorial, Borges alerta seus leitores para o fato de que tal consideração nãoé de todo inadequada, mas sim que esta correspondência pode ser demasiado direta ou pode ainda levar-nos a falsas conclusões, produzindo imagens especulares, inferências equivocadas.

\section{II}

Por volta dos anos 50, Borges desentranharia do fundo de sua cegueira uma esplêndida visão, um insight incomodamente claro daquilo que passará a ser ao mesmo tempo a confirmação do seu passado e presente e a profecia do seu futuro. A surpresa desse momento epifânico deve tê-lo feito sentir-se como Enéias, naquela justa ocasião em que lhe é revelado um fragmento de seu passado em pintura no templo de Juno. Esse alumbramento ocorreu depois de Borges ter lido a Divina Commedia. Nessa obra, o escritor argentino viu uma fração de seu passado refletida: sua frustrada relação amorosa e platônica com Estela Canto e como a presença dessa derrota iria assombrá-lo durante muitos anos ainda, já sem nenhuma esperança de que a sua cansada memória pudesse apagar as impressões da perda. Para recordar o prazer e o sofrimento desta relação, Borges escreve então o relato autobiográfico "El Aleph" (15). O conto coincide com um período de sua vida durante o qual ele produz nove comentários sobre a obra de Dante.

$\mathrm{O}$ que significa para ele escrever sobre a Divina Commedia? Borges, cético quanto à idéia da originalidade em literatura, testemunha agora o ciclo da vida humana e da tradição literária da qual ele também participa. Dessa perspectiva, participarsignifica transgredir; e, conseqüentemente, uma leitura borgiana de Dante estaria destinada a tornar-se criticamente menos proveitosa do que uma leitura dantesca de Borges. A prefiguração que faz Dante da fama e da influência de sua obra e também 
a narração de sua perda pessoal serão perpetuadas pelo escritor argentino. Mas, como era de esperar, Borges não menciona, porque não pode mencionar, Dante no seu conto, talvez porque, como afirmaria Bloom, "Dante é tão forte - teórica, psicológica e espiritualmente falando - que ele debilita a autoconfiança de [Borges]" (16). Assim, torna-se evidente que aqui há algo mais que um mero caso de "ansiedade da influência”. Borges silencia diante das assombrosas similaridades entre os mundos psicológico e espiritual de Dante e o seu.

Ao perder Beatriz, e apesar da humilhação sofrida, Dante não deixaria de amá-la até o final da sua vida. Continuar demonstrando que a existência amorosa do poeta italiano é neste particular semelhante à de Borges não deixa de ser um exercício mecânico como também um tanto óbvio. Portanto, preferimos argumentar que, além de fazê-lo através de "El Aleph" e dos comentários sobre a Divina Commedia, Borges se revela ao leitor na medida em que suas observações sobre Dante se tornam observações sobre si mesmo. Não questionaremos o nível totalmente consciente ou inconsciente dessa leitura que empreende Borges a partir de Dante. Simplesmente a consideraremos como uma estratégia empregada pelo argentino, pois a expressão "estratégia" (de leitura) nos permite carregá-la de um certo grau de motivação e objetivo da parte dele.

Bem poucos autores agradaram tanto a Borges, por suas vidas e obras, como Dante. Conta-nos o próprio Borges que ele não queria escrever os Nueve Ensayos Dantes$\cos$ nos moldes acadêmicos, coisa que teria sido muito mais fácil para ele. Ao contrário, optou - isto ele não nos diz - por uma leitura interpretativa de caráter pessoal e intimamente ligada a sua experiência de vida. Além do mais, seus comentários deveriam ser estritamente literários, mas o desejo primeiro deu imediatamente lugar a uma força muito mais significativa para ele: sua incursão pela vida de Dante, como autor. Não seria demasiado dizer que Borges penetra a Divina Commedia obliquamente, por um ângulo singular a partir do qual rea- liza nove leituras originalíssimas dos melhores momentos do poema. E ainda, se quisermos enxergar o verdadeiro alcance dessas leituras, teremos que a admitir que, além de serem comentários no melhor sentido da crítica literária, são também um modo de enfrentar-se com "um demônio pessoal, um caso mal resolvido". Mas isso nãoé tudo. Somente uma extraordinária confluência de circunstâncias poderia ter dado à luz um dos seus contos mais célebres, "El Aleph", no qual ele antecipa a presença de Dante nos seus escritos posteriores.

Publicado, primeiramente, em Sur (1945), "El Aleph" foi dedicado a Estela Canto, a qual por sua vez nos conta sobre a origem do conto:

"Me dijo que quería escribir un cuento sobre un lugar que encerraba 'todos los lugares del mundo' y que quería dedicarme ese cuento. Fue la primera alusión a 'El Aleph'. [...] Él sugirió que yo podría ayudarlo en la enumeración de los objetos que quería nombrar.

$$
[\ldots]
$$

Dos o tres días después vino a casa una mañana, trayendo un paquete que, según dijo, contenía un objeto que mostraba 'todos los objetos del mundo'. El objeto se llamaba el Aleph. No dijo que el Aleph era la primera letra del alfabeto hebreo. Para él era ese objeto una puerta abierta a lo imposible.

$$
\text { [...] }
$$

Me repetía que él era Dante, que yo era Beatrice y que habría de libertarlo del infierno, aunque yo no conociera la naturaleza de ese infierno.

\section{[...]}

Estaba exaltado; citaba poemas en inglés, en español, tercetos de la Divina Comedia" (Borges a Contraluz, pp. 94-5) .

A presença da retórica da autofiguração de Dante na obra de Borges é tão incisiva que seria quase impossível dar uma idéia dela aqui (17). Ao discutir a relação entre a Commedia e "El Aleph”, Emir Rodríguez Monegal estabeleceu o seguinte protocolo de leitura: personagens, Hadík I"E Milagro Secreto") que se encaixa perfeitamente em "E Aleph": "En el argumento que he bosquejado, intuía la invención más apta para disimular sus defectos y para ejercitar sus felicidades, posibilidade de rescatar (de manera simbólical lo fundamental de su vida" IOC, I 511

16 Bloom, p. 78. Ver também Thiem, p. 103 e Menocal, p. 165

17 Fiquemos só com alguns dos seus escritos em que as refe rências ou alusões a Commedia são evidentes: os poemas "Del Infierno, de Cielo", "Poema Conietural", "E Hambre" "Elegía" IEl Otro el Mismol, "Infierno, V, 129", "Nota para un Cuento Fantás tico" (La Cifra); os contos "La Otra Muerte", o próprio "E Aleph" (El Aleph) e logicamente, os Nueve Ensayos Dantescos e mais "L Divina Comedia" em Siete Noches. 
“ 'El Aleph' es una reducción paródica de la Divina Comedia. Desde ese ángulo, 'Borges' es Dante, Beatriz Viterbo es Beatrice Portinari (tan desdeñosa del poeta florentino como la argentina lo es del autor) y Carlos Argentino Daneri es a la vez Dante y Virgilio. Su nombre Daneries una abreviatura de Dante Aligheri, como Virgilio es un poeta didactico y un guía para la visión del otro mundo. [...] Estela (es decir, Stella) fue la palabra elegida para terminar cada uno de los tres Cantiche de la Divina Comedia, y Canto corresponde a cada división en los cánticos. Pero al colocar en la última línea del texto la frase 'A Estela Canto', Borges escribiría también 'Canto a Estela'. Cuando concibió ese cuento, estaba más que dispuesto a hacerlo. Como homenaje privado le regaló el manuscrito, de microscópica letra" (Borges: una Biografía, pp. 372-3).

Referindo-se ao ensaio "Encuentro en un Sueño", originalmente publicado no jornal La Nación, de 3 de outubro de 1948 (18), Rodríguez Monegal acrescenta:

"Tras describir el episodio e insistir en la forma en que Beatrice allí se burló de Dante y le humilló, cita una observación hecha en 1946 por el crítico alemán Theophil Spoerri: 'Sin duda el mismo Dante había

8 Reeditado depois como prólogo a uma edição espanhola da Divina Commedia (1949) mais tarde em forma de ensaio na primeira edição de Otras Inquisiciones (1952), para, finalmente, aparecer de novo en Nueve Ensayos.

19 Para a noção de autobiografia como representação, ver a ex celente introdução de Sylvia Molloy em At Face Value.

20 As observações de Menocal derivam de um comentário de Thiem (p. 1 18). Todavia, é difícil concordar com este no que se refere à visão paródica que tem Borges da Commedia lp. 109). Para mais uma leitura do modo como Borges interpreta as múltiplas figurações $d$ Dante, ver "El Noble Castillo del Canto Cuarto", "El último Viaje de Ulises" e "El Verdugo Piadoso" em Nueve Ensayos.

21 Ver, por exemplo, as interpretações de Bloom e Menocal.
Daneri (até certo ponto, é claro, é justamente isto o que preclui que o texto seja considerado uma paródia" (p. 160) (20).

Apesar disso tudo, Rodríguez Monegal entendeu muito bem o alcance e o propósito do conto como projeto literário, porque "su [de Borges] interpretación del encuentro entre Beatriz y Dante integró el tejido de su relato" (idem, p. 374). No entanto, o crítico uruguaio ignorou a estratégia discursiva adotada para este conto, a mesma estratégia que ele já havia identificado em outro conto, "El Zahir": "Pero como Borges era Borges, debía disimular una fijación erótica tras una narración erudita, cabalística" (idem, p. 372). Ora, deixando de lado o que pode haver de exagero nesse tipo de fixação do escritor argentino, poderíamos dizer que ela é essencialmente romântica, no melhor dos casos platônica, e que se perde facilmente em meio às distrações dos jogos literários de "El Aleph". Mais sensato seria considerar, no plano geral do conto, o poema de Dante interagindo discursiva e biograficamente com o discurso de Borges. A primeira proposta é mais fácil e já foi parcialmente realizada pela crítica (21). A segunda, contudo, exige um método pouco convencional e talvez não tão acadêmico que nos permite utilizar informações da escritora e tradutora argentina Estela Canto no seu livro Borges a Contraluz. (1989). Memorialística e por vezes ingênua nas suas linhas gerais, essa obra narra alguns dos momentos mais significativos e apaixonantes de sua relação com o escritor e dá a lume versões fac-similares de uma série de cartões-postais e cartas amorosas que lhe foram enviadas por Borges. É justamente naintimidade dessa correspondência que se encontram respostas que talvez possam nos ajudar a resolver alguns problemas textuais do famoso conto. Uma leitura de "El Aleph", como conte à clef, revelaria ainda alguns dos seus melhores segredos.

Inicia-se o relato, por exemplo, com a referência à morte de alguém que o narrador-personagem Borges amava, mas que disfarçadamente pretende esquecer. "Cuál es el hecho más triste, el más melancólico que puede registrarse?", se pergunta o es- 
critor argentino em um de seus ensaios sobre Edgar Allan Poe. "Ese hecho"-responde ele - "tiene que ser la muerte de una mujer hermosa. Quién puede lamentar mejor ese hecho? Desde luego, el amante de esa mujer" (Borges Oral, p. 70), conclui Borges. Estas duas perguntas servem para pautar também o seguinte trecho de "El Aleph":

"[...] el hecho me dolió, pues comprendí que el incesante y vasto universo ya se apartaba de ella y que ese cambio era el primero de una serie infinita. Cambiará el universo pero yo no, pensécon melancólica vanidad; alguna vez, lo sé, mi vana devoción la había exasperado; muerta, yo podía consagrarme a su memoria, sin esperanza, peró también sin humillación” (p. 617).

O tom confessional dessas linhas assinala o profundo sentimento da perda mas sobretudo o da rejeição. Borges, narradorpersonagem, sente-se humilhado como teria se sentido na vida real, conforme mostra a sua última carta a Estela:

“Wednesday morning

\section{Querida Estela:}

No hay ninguna razón para que dejemos de ser amigos. Te debo las mejores y quizálas peores horas de mi vida y eso es un vínculo que no puede romperse. Además, te quiero mucho. En cuanto a lo demás..., me repites que puedo contar contigo. Si ellofuera obra de tu amor, sería mucho; si es un efecto de tu cortesía o de tu piedad, I can't decently accept it. Loving or even saving a human being is a full time job and it can hardly, I think, be successfully undertaken at odd moments. Pero... a qué traficar en reproches, que son mercancía del Infierno? Estela, Estela, quiero estar contigo, quiero estar silenciosamente contigo. Ojalá no faltes hoy a Constitución. Georgie" (Borges a Contraluz, p. 154).

Escrito por um missivista um tanto desesperado, como acabamos de ver, este texto bilíngüe oscila entre o espanhol e o inglês. Atendendo a um expediente que lhe permitiu dizer certas coisas em espanhol, que teriam sido demasiado íntimas e confessionais, Borges consistentemente muda de idioma do espanhol para o inglês toda vez que seus sentimentos mais profundos afloram. Sem dúvida, há algo oculto aqui. Pelo que a ausência de selos parece indicar, quando redigidas em cartões-postais, essas breves notas de amor possivelmente não foram expostas no correio, pois parece que o autor as enviou em envelopes. Entretanto, produzir essas mesmas mensagens em espanhol teria sido problemático para ele. Claramente, Borges esperava que, com o uso do inglês, ficasse resolvido o problema da pieguice dos sentimentos que seu racionalismo recalcitrante severamente censurava. Por isso é que os seus poemas "Two English Poems" (OC, I, p. 861) permitem a entrada de um eu lírico ostensivo que raramente está presente no conjunto de seus poemas em espanhol. Sob a máscara da língua inglesa, Borges se autoriza um tom intimista, uma exaltação lírica e uma confissão pessoal que de outra forma teriam sido impensáveis em toda sua obra, antes ou depois desses dois originais poemas amorosos (22).

No decorrer do livro de Estela Canto, através de um processo acumulativo, o leitor vai percebendo como a rejeição por parte da amada poderia tê-lo ferido. Parafraseando Borges, poderíamos dizer que Dante professou por Beatriz, assim como Borges por Estela, uma autêntica idolatria; que elas em certa ocasião os humilharam e em outra os ignoraram são fatos registrados na Vita Nuova e em Borges a Contraluz. Uma vez mortas e perdidas para sempre as duas Beatrizes (e a morte de Beatriz Viterbo é obviamente metafórica, porque significa a perda de Estela), Dante e Borges começaram a brincar com a idéia de encontrá-las, para assim mitigar a enorme tristeza de ambos. Beatrice Portinari e Beatriz Viterbo existiram de modo infinito para Dante e Borges, respectivamente. Dante e Borges existiram muito pouco, talvez nada para elas (OC, II, p. 371).
22 Para o uso que faz Borges do inglês para ocultar seus sentmentos, ver Estela Canto, pp. 98,146 e 157. O tema da omissão em Borges vai além das fronteiras autobiográticas que estamos abordando aqui. A omissão borgiana da pre sença de Dante em "El Aleph" oiestudada de maneira exemplar por Jon Thiem. Ver Thiem, pp. 103, 108 e 113. 
Nas passagens iniciais de "El Aleph", a imagem de Beatriz, captada pelas muitas fotografias nas quais ela posa de várias maneiras e com diversas pessoas, torna-se menos uma visão multifacetada da personagem do que uma frívola representação congelada no tempo. Igualmente frívola é a enumeração oferecida pelo narrador: "Beatriz, Viterbo, de perfil, en colores, Beatriz, con antifaz, en los carnavales de 1921; la primera comunión de Beatriz; [...] Beatriz de frente $v$ de tres cuartos, sonriendo, la mano en el mentón..." (OC, I, p. 617). Definitivamente, a realidade parece ter invadido a ficção de Borges, como demonstra a imagem que dela construiu ele: "Nunca Estela, me lhe sentido más cerca de ti; te imagino y te pienso continuamente, pero siempre de espaldas o de perfil" (Canto, p. 125). Aliás, um curioso hábito do narrador de "El Aleph" se entrecruza, de maneira exemplar, com o de Borges na vida real: "No estaría obligado como otras veces, a justificar mi presencia con módicas ofrendas de libros: libros cuyas páginas, finalmente, aprendí a cortar, para no comprobar, meses después, que estaban intactos" (OC, I, pp. 617-8).

O gesto é relativamente simples na vida real: Estela Canto recebendo um livro todas as manhãs, quando Borges passava por sua casa para visitá-la. Não é sem um quê de ironia que o narrador insinua o desinteresse (quando comparado ao seu) da namorada pelos exemplares presenteados diariamente. A própria Estela é quem confirmará o hábito: satirizado como rival de Borges, - medíocre Carlos Argentino Daneri..." (p. 480). Um erro factual levou Bloom a conside rar uma aproximação de "E Aleph" ao poema épico nerudiano, Canto General. "E Aleph", ao contrário do que diz Bloom, foi primeiro publicado na revista Sur em 1945 e e não em 1949, data da sua publicação, outra vez, em livro. A posição de Borges com respeto a Rubén Darío é contraditó ria. Durante os seus anos ultraístas, em princípios da dé cada de 20 , Borges o repudiou. Mais tarde, o argentino ira aclamá-lo. Ver também a discussão de Thiem (pp. 110-1) sobre a ambivalência de Borges acerca de La Tierra. jável economia narrativa, fez com que Borges certa vez afirmasse que tinha "fantaseado una obra mágica, una lámina que también fuera un microcosmos; el poema de Dante es esa lámina de ámbito universal" (OC, II, p. 343).

$\mathrm{Na}$ encruzilhada da vida com a ficção está situada outra personagem. Trata-se de Carlos Argentino Daneri, outro alter ego de Borges (além daquele homônimo Borges), primo-irmão de Beatriz Viterboe autor do poema épico La Tierra. Se for verdade, então, que Daneri é Borges, a atitude e a poesia daquele contradizem essa identidade. Ademais, a relação entre os dois indivíduos no conto é tensa e poderia levarnos a comparar a atitude algo arrogante do Borges ficcional para com Daneri com a do auto-elogio de Dante no seu poema. Mas tal arrogância, essencialmente, não existe, porque a principal crítica que faz Borges de Daneri tem a ver menos com sua pessoa que com sua obra. De fato, se há realmente esse primeiro tipo de crítica, Borges estaria realizando-a com um certo desdém, uma espécie de ciúme que se manifesta às vezes através da sua calculada indiferença com respeito a Beatriz. Esta é uma área problemática no universo psicológico do Borges ficcional do conto, em que o desafeto inevitavelmente se transforma em desejo; e até mesmo num plano intelectual, a comparação se torna ambivalente. Focalizando-se insistentemente na linguagem pomposa e afetada que Daneri emprega no seu vasto e detestável poema, Borges desfere o seu ataque a um tipo de literatura que estaria melhor representada pelo exaustivo poema épico Polyolbion, de Michael Drayton, cuja prolixidade e chatice são amargamente criticadas. Seria necessário notar também a acrimoniosidade com que o Borges narrador critica os resquícios do modernismo hispano-americano exemplificados pela poesia de Rubén Darío, por exemplo, com respeito ao uso exagerado de epítetos que corroboram um certo preciosismo modernista freqüentemente repudiado por aquele Borges ultraísta no começo de sua carreira (23).

Além do mais, essa mesma crítica ali- 
menta o conceito de paródia, entendido de modo positivo e negativo - se neste último caso o poema de Drayton for tomado como modelo de má literatura, como ocorre também com La Tierra (24). E onde estaria, então, o elemento positivo ou o encômio ao poema de Daneri? Justamente na escolha de uma estrofe contendo um verso que celebra a idéia do aleph: “... el voyage que narro, es ... autor de ma chambre" (25); e, também, no desejo de Borges de criar a falsa impressão de que a totalização é repudiável ("Éste se proponía versificar toda la redondez del planeta..." (26); e, ainda, no debatidíssimo papel do crítico literário, cuja ressonância horaciana é clara ("equiparó a esas personas, 'que no disponen de metales preciosos"") (27); e, depois, na identidade entre o mau poeta e o igualmente mau crítico ("Comprendí que el trabajo del poeta..."); e, finalmente, naquele grandioso "aleph", sempre presente e aludido,e assim nunca diretamente mencionado, no poema de Daneri: a Divina Commedia.

Antes de descer ao porão da casa da Rua Garay para examinar o aleph, Borges espera para ser atendido por Daneri na sala de visitas onde há um grande e solitário retrato de Beatriz sobre o piano. Estamos exatamente na metade do conto e seu clímax está ainda para ser alcançado com a ajuda daquela visão deslumbrante do aleph. Esta espera sintetiza, magnificamente, os sentimentos e o propósito do narrador como escritor; e de Borges, como autor do conto. Crucial para sua compreensão é este preciso momento da fusão dos papéis: Borges, dentro e fora de seu conto. É aqui também que a magia da ficção produz seus efeitos encantatórios, diante dos quais o leitor já não consegue dissociar aquilo que pertence ao mundo da imaginação daquilo que faz parte da realidade, justamente porque a intensidade dos sentimentos faz com que eles coincidam e apareçam mesclados ou cruzados.

Na privacidade de uns poucos minutos privilegiados, enquanto aguarda o amigo que virá recebê-lo, Borges-personagem se dedica a contemplar o retrato da antiga mulher amada e num desespero de ternura se aproxima dele para proferir as palavras mais patéticas de toda a sua obra: "Beatriz, Beatriz Elena, Beatriz Elena Viterbo, Beatriz querida, Beatriz perdida para siempre, soy yo, soy Borges" (OC, I, p. 624).

Ver Beatriz outra vez, embora emoldurada e congelada no tempo, é muito mais do que ver. A paixão, o desespero, o abandono, a solidão e a profunda melancolia derivados de uma ausência de amor recuperável, são expressos aqui como em nenhum outro texto seu (28). O único estado de espírito que se aproximaria talvez mais desses sentimentos é aquele também registrado nos momentos de grande paixão que Borges sentiu por Estela:

"Thursday, about five.

I am in Buenos Aires. I shall see you tonight, I shall see you tomorrow, I know we shall be happy together (happy and drifting and sometimes speechless and most gloriously silly), and already I feel the bodily pang of being separated from you, turn asunder from you, by rivers, by cities, by tufts of grass, by circumstances, by days and nights. These are, I promise, the last lines I shall allow myself in this strain; I shall abound no longer in self-pity. Dear love, I love you, I wish you all the happiness; a vast and complex and closewoven future of happiness lies ahead of us. I am writing like some horrible prose poet; I don't dare to reread this regrettable postcard. Estela, Estela Canto, when you read this I shall be finishing the story I promised you, the first of a long series. Yours, Georgie" (p. 143; no original em inglês).

Que retórica e estilisticamente essas mesmas palavras ("Estela, Estela Canto...") e o gesto verbal ("I am writing like some horrible prose poet") apareçam nos dois lugares, no postal e em "El Aleph", dramatizam o paralelo entre Borges e Daneri, e entre Borges-autor e Borges-narrador do conto.

Convenhamos, a ficção é uma arma perigosa. Depois de perdê-la na vida real, aquele Borges desesperançado começa a buscar a imagem de Estela Canto no mun-
24 Ver Linda Hutcheon, capítulo 2.

25 A frase em francês provém do título do livro de Xavier de Maistre, Le Voyage Autour de ma Chambre (1794). A relacão entre a obra de Maistre a Commedia (Inferno, 33) se faz evidente no capítulo 23 de Le Voyage.

26 Aliás, o espírito totalizante da Commedia se reflete tanto en La Tierra como em "El Aleph".

27 Ver Horácio, linhas 301-308, pp. 747-77.

28 A caracterização que oferece Rojas desse momento como "melodramático" (p. 81) está obviamente, em franca oposi ção à nossa. 
29 Ver as estrofes 32-55. Borges estava muito bem familiarizado com a obra de Juan de Mena. Ver OC, I, p. 647; E Tamaño de mi Esperanza, p. 48

30 Consultar María Rosa Lida de Malkiel, pp. 17-19.

31 Uma estrofe de La Tierra, que aborda a zona austral do glo bo, estaria indicando um possivel eco de Laberinto de Fortuna. Ver a estrofe 34 no poema de Mena. Outro desenvolvimento notável desse topos se en contra no canto 27 de La Araucana, II (1580) de Alonso de Ercilla. Esse canto se inicia com uma defesa sobre a brevdade, uma alusão a um objeto que, embora muito maior que aleph de Borges, contém todas as partes do mundo, e finalmente - com intenção já autobiográfica - oferece uma visão telescópica da casa do autor na Espanha. Compare-se: sua intolerância à prolixidade, o minúsculo objeto que, contendo todo o universo, contém tam bém a própria vida do autor. $\mathrm{O}$ topos, além de aparecer no Laberinto de Mena, foi explo rado também por Bernardo de Balbuena em El Bernardo, Victoria de Roncesvalles.. (1624).

$32 \bigcirc$ uso que fazemos aqui da noção de "visão global" tem a ver menos com a idéia da inefabilidade, conforme Thiem a apresenta, do que com totalização, deseio enciclopedico e épico. Para uma discussão proveitosa do assunto, consultar as últimas quatro páginas do ensaio deste crítico.

33 "A tradição afirma que Homero era cego", escreve Vico, "e que da cegueira ele tirou o seu nome, o qual em dialeto jônico significa 'cego"'. Consultar The New Science, p. 322

34 Stefanini, p. 55. Consultar também Thiem, pp. $112-3$ e Davi Arrigucci Jr., p. 208. do do conto, como Daneri nos faz lembrar ("[...] muy en breve podrás entablar un diálogo con todas las imágenes de Beatriz" (OC, p. 624). E lá, a bela Estela-Beatriz se encontra envolta numa fina névoa, não totalmente por acaso; e o pobre Borges terá que irremediavelmente lidar com a idéia do fracasso. Mas é ainda muito cedo para sentirmos pena dele. O seu enorme esforço para erigir um monumental labirinto que o ajudasse a encontrá-la não terá sido em vão, e quando Borges se move no ambiente de sua literatura, ele sempre consegue nos surpreender. Porque é aqui, exatamente, quando o leitor já não pode deixar de pensar na descrição que faz o nosso autor da situação de Dante: “Ausente para siempre de Beatriz, solo y quizá humillado, imaginó la escena para imaginar que estaba con ella" (idem, p. 374).

Antes de revelar o aleph ao leitor, Borges realiza uma enumeração whitmaniana com um ritmo realmente vertiginoso e, depois, nos leva a uma coda eruditíssima, mostrando-nos outros “alephs". A idéia da enumeração caótica das coisas, vistas por Borges através do aleph de Daneri no porão, poderia ser atribuída ao poema medieval Laberinto de Fortuna (1444), de Juan de Mena (29). Sensibilizados pela urdidura de um conto que é ao mesmo tempo cerebral e encantatório, ornado com uma riqueza de detalhes e cinzelado pela elegância da escritura borgiana, nós leitores inevitavelmente retornamos à Divina Commedia, que com toda probabilidade influenciou a obra de Mena (30). Qualquer que seja a conclusão que se possa tirar dessa influência o topos da imagine mundi no Laberinto e a maneira anafórica como o poema ressalta o ato de ver ("Yovi") não podem passar inadvertidos (31).

Os atributos proféticos do poema de Dante permeiam a narrativa de Borges mais uma vez, autorizando-lhe antecipar no conto um gesto simbólico que anos mais tarde, quando ele já estará cego, será o seu único modo de ver: "ver nas trevas". No contexto de sua cegueira, o ato reiterativo de ver, do Borges ficcional ("Yo vi") em "El Aleph", recobra aquela qualidade visionária de sua poesia à qual nos referíamos anteriormente, fermentada pela aproximação ao poema de Mena e coroada pela visão totalizante e totalizadora da poética de Dante (32). Ver nas trevas equivale a ver de modo global, épica e homericamente, mas também significa a compensação pela perda da visão que nunca, de fato, pareceu incomodar o escritor argentino completamente (33): "Verás el color amarillo y sombras y luces. No te preocupes. La ceguera gradual no es una cosa trágica. Es como un lento atardecer del verano" (OC, II, p. 16).

Estas palavras, pronunciadas pelo autor na idade dos 72 anos, remetem-no à condição a que ele sempre pertenceu: o elementar e primordial Borges de Luna de Enfrente, onde o crepúsculo ou o final do dia, como tropo, impregna a sua primeira poesia. Borrando, sombreando a paisagem e os objetos em seus poemas, Borges, como Milton, nos ensina a ver sem ver. Mas, é claro, essa lição não deve ser interpretada como ilusão. Omissões, vazios e trevas abarcam mais com menos, como sugere Ruggero Stefanini, o que corresponderia a outro paradoxo: o de que Borges realiza uma contração narrativa ideal para que seus leitores possam expandi-la mais tarde (34).

Seria absurdo negar em "El Aleph" a plausível relação entre a Divina Commedia e este conto de Borges, no que diz respeito à visão totalizadora de Dante. Como já observamos neste ensaio, Borges não faz nada menos que construir o seu eu poético em Dante e a partir de Dante. Ao fazê-lo, o escritor argentino escolheu um caminho tortuoso para a sua "não-biografia", constantemente recordando-nos que algumas das coisas gloriosamente dolorosas da vida podem ser somente aludidas e nunca diretamente narradas. A sua confiança no poder que tem a linguagem de produzir novas realidades ou de renomeá-las o levou ao paraíso seguro da literatura, ali onde ele pôde escrever tudo ou não mencionar nada sobre si mesmo. Como Dante, Borges entendeu a linguagem como meio de conhecimento de si próprio e das coisas do mundo; como Dante, ele construiu um labirinto 
tão desproporcional e vasto para distrair-se da dor de haver perdido sua "Beatriz"; e, finalmente, como Dante, ele compreendeu também que nem mesmo o seu vasto co- nhecimento e erudição, nem a admirável literatura produzida por ele seriam suficientes para mitigar a saudosa e insuportável memória de sua amada.

\section{BIBLIOGRAFIA}

ALAZRAKI, Jaime. Jorge Luis Borges. Madrid, Taurus, 1976.

ARRIGUCCI JR., Davi. "Da Fama e da Infâmia (Borges no Contexto Literário Latino-americano)", in Enigma e Comentário. São Paulo, Companhia das Letras, 1987, pp. 193-226.

BALDERSTON, Daniel. Out of Context. Durham/Londres, Duke UP, 1993.

"The 'Fecal Dialectic': Homosexual Panic and the Origin of Writing in Borges", in Emile L. Bergmann e Paul Julian Smith (eds.), Entiendes?: Queer Readings, Hispanic Writings. Durham/London, Duke UP, 1995. BLO0M, Harold. The Western Canon. Nova York/San Diego/Londres, Harcourt Brace \& Company, 1994. BORGES, Jorge Luis. Obras Completas (OC, I). Buenos Aires, Emece Editores, 1974. . Obras Completas (1975-1985) (OC, II). Buenos Aires, Emece Editores, 1989. . Six Problems for Don Isidro Parodi. Trad. de Norman Thomas di Giovanni. New York, 1972. . The Aleph and Other Stories. Londres, Jonathan Cape Ltd., 1971. Other Inquisitions 1937-1952. Trad. de Ruth L. C. Simms. Austin, Texas, University of Texas Press, 1964. . Textos Cautivos. Ed. de Enrique Sacerio-Gari e Emir Rodríguez Monegal. Barcelona, Tusquets, 1986. . El Tamaño de mi Esperanza. Buenos Aires, Seix Barra/Biblioteca Breve, 1994. Borges, Oral. Barcelona, Bruguera, 1980. . Borges a Reader. Ed. de Emir Rodríguez Monegal e Alastair Reid. Nova York, E. P. Dutton, 1981. . Borges el Memorioso. Interview with Antonio Carrizo. Mexico, Fondo de Cultura Económica, 1983. . "Beatrice's Last Smile", in Dispositio 18, 45, 1993, pp. 23-5. Trad. por Virginia Múzquiz. . Borges in Revista Multicolor. Ed. de Irma Zangara. Buenos Aires, Atlántida, 1995.

CANTO, Estela. Borges a Contraluz. Madrid, Espasa Calpe, 1989.

HORACE. Satires, Epistles, Ars Poetica. Trad. de H. Rushton Fairclough. The Loeb Classical Library. Cambridge, Mass./ Londres, Harvard UP/William Heinemann Ltd., 1966.

HUTCHEON, Linda. A Theory of Parody. Nova York/Londres, Methuen, 1985.

LIDA DE MALKIEL, Maria Rosa. Juan de Mena: Poeta del Prerrenacimiento Español. México, El Colegio de México, 1984. MAISTRE, Xavier de. Le Voyage Autour de ma Chambre. Ed. de J. Squair e J. MacGillivray. Toronto, The W. J. Gage Company, 1894.

MENA, Juan de. Laberinto de Fortuna. Ed. de John G. Cummins. Madrid, Cátedra, 1990.

MENOCAL, María Rosa. Writing in Dante's Cult of Truth. Durham/Londres, Duke UP, 1991.

MOREIRAS, Alberto. "Borges y Estela Canto: la Sombra de una Dedicatoria", in Journal of Interdisciplinary Literary Studies 5, 1, 1993, pp. 31-46.

MOLLOY, Sylvia. At Face Value: Autobiographical Writing in Spanish America. Cambridge, Cambridge UP, 1991. Duke UP, 1994.

. Signs of Borges. Trad. e adaptação de Oscar Montero em colaboração com a autora. Durham/Londres,

PAZ, Octavio. "El Desconocido de Si Mismo (Fernando Pessoa)", in Cuadrivio. México, Joaquín Mortiz, 1976, pp. 131-63.

RODRÍGUEZ MONEGAL, Emir. Jorge Luis Borges: a Literary Biography. E.P. Dutton, Nova York, 1978. . Borges por Él Mismo. Caracas, Monte Ávila, 1991.

. Borges: una Biografía Literaria. Trad. de Homero Alsina Thevenet. México, Fondo de Cultura

Económica, 1987.

ROJAS, Santiago. "El Desdoblamiento Creador-personaje en Borges: Usos y Efectos de Creación", in Confluencia 11 , 1995, pp. 75-88.

STEFANINI, Ruggero. “Dante in Borges: L'Aleph, Beatnz, e II Sud.", in Italica 57, 1980, pp. 53-65.

THIEM, Jon. "Borges, Dante, and the Poetics of Total Vision", in Comparative Literature 40, 2, 1988, pp. 97-121. VICO, Giambattista. The New Science. Ed. de Thomas Goddard e Max Harold Fisch. Ithaca/Londres, Cornell UP, 1984. WHITE, Hayden. Tropics of Discourse: Essays in Cultural Criticism. Baltimore/Londres, The Johns Hopkins UP, 1978. 